\section{It Is Time For The Scholars To Be Heard}

\section{Stephen Frantzich}

Professor of Political Science, U.S. Naval Academy and President of the Computer Users Section of the American Political Science Association

Do you use government documents, statistics, or data? Are you anxiously awaiting new and technologically improved access to this information? Don't wait in silence. During the 101 st Congress, serious consideration will be given to government-wide policies concerning public access to government information in electronic form.

New technologies, largely based on the computer, offer the promise of better and more timely government information, but new formats could also increase information inequality. For example, the impact on congressional scholars could be significant. Traditionally public documents may well not exist in the format we are used to. The Government Printing Office has already announced plans to publish the bound Congressional Record on CD-ROM as a replacement for the hard copy version. CD-ROM is an ideal format allowing

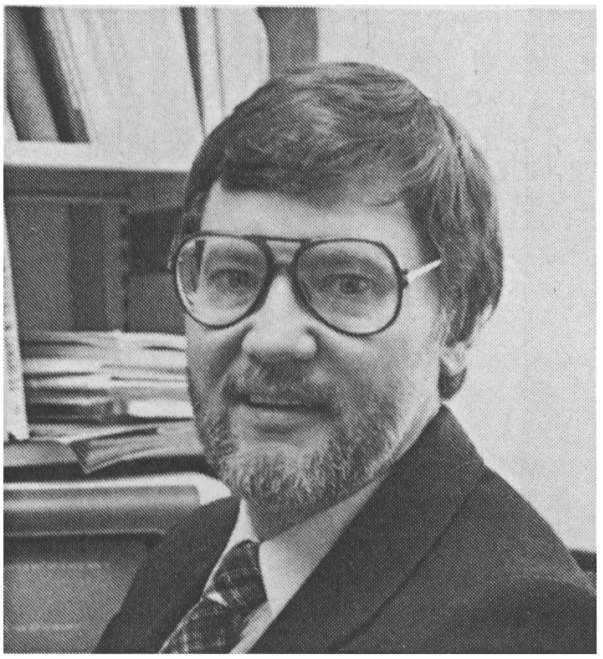

STEPHEN FRANTZICH sophisticated search and retrieval for those who have access to the technology. Individuals and organizations without the resources or skills to use this technology will be disadvantaged. The Digest of General Bills and Resolutions used to be printed 5-10 times per year providing a relatively timely source of bills status information. As Congress moved toward on-line access for its internal use, hard copy publication was reduced to once a year, thus making the document only useful for historical re. search. In other realms, Congress had made electronic tapes of its materials available to commercial vendors for resale. While the vendors have added sophisticated search and retrieval software to make the data more accessible, these enhancements are expensive (often over $\$ 5,000$ for congressional data only). We are rapidly developing two classes of users, those who can instantaneously search and analyze massive data banks (such as the full text of the Congressional Record on-line), and those citizens and scholars forced to use the traditional, cumbersome, and inefficient methods. The story of absolutely or relatively reduced access repeats itself across the whole range of government information.

A recent study by the U.S. Congress Of. fice of Technology Assessment informing the Nation: Federal Information in an Electronic Age, available from the Government Printing Office for $\$ 14.00$ - GPO stock number 052-003-01130) outlines both the potential and pitfalls of electronic access. It frames a number of questions committees such as the Joint Committee on Printing. House Committee on Government Operations, and Committee on House Administration will have to face up to in the near future.

The battle lines are already being drawn. Government agencies generally want their information disseminated in the most efficient manner, but do not want to lose control. The commercial vendors (most vocally represented by the Information Industry Association) largely take the position that government has neither the right nor the capability of disseminating its information in electronic form. The library community, especially representatives of the 1400 depository libraries, are fighting to main- 
tain their position as the providers of an information "safety net," but recognize that without some major changes they will be bypassed by new technology. The scholar. ly community-some of the most consistent users of government information--are neither organized nor vocal. It is clear that we are likely to wake up to find that some of our key government information is no longer available, or that the most useful information is only available at a commercial price beyond our means.

In defining both the scholar's stake and position in this on-going battle it is important that we recognize that we neither can nor should retard movement toward more government information being provided in electronic formats just so that we can remain comfortable in our ability to use existing formats. Our position must be one of hailing the potential of new technol. ogy, but being ever watchful for examples where applications of technology reduce our access and/or competitive advantage. There seems to be enough room in the government information realm for a healthy mix of formats and delivery mechanisms. Scholars need to fight for their rights to continue to play on the new information playing field. Our potential allies and opponents are neither fixed nor always clear. It is not a matter of lining up against the vendors in favor of direct government dissemination, but rather seeking ways in which the unique needs and resources of the academic community can be better served through vendor recognition and accommodation. We should support the efforts of the library community as our advocates, but recognize that our interests might lie in revising the ways in which libraries traditionally collect and/or disseminate information. We need to make ourselves known to the government agencies whose information we use, sensitizing them to our needs and desires, and making ourselves a visible constituency.

The electronic information age offers tremendous potential for creating a better informed society. Some scholars are already reaping the benefits and frustrations of the "electronic ivory tower," but most are just beginning to recognize the potential advantages and dangers. Our first step lies in understanding the issues outlined in the OTA study as they apply to our interests. The next step lies in activating and sensitizing our professional organizations. Finally, as the issues develop into policy in the legislative process we must make our. selves heard both through our professional organizations and individually.

\section{Southern Political Science Association 1988 Manning $J$. Dauer, Jr. Award To Evron M. Kirkpatrick}

\section{Walter E. Beach}

Senior Staff Member, Brookings Institu tion, and Chairperson, Manning J. Dauer Committee

In recognition of the nearly fifty years of distinguished service of Manning J. Dauer to the Southern Political Science Association, the Association established the Manning J. Dauer, Jr. Endowment Fund shortly after his death in 1987. The fund provides

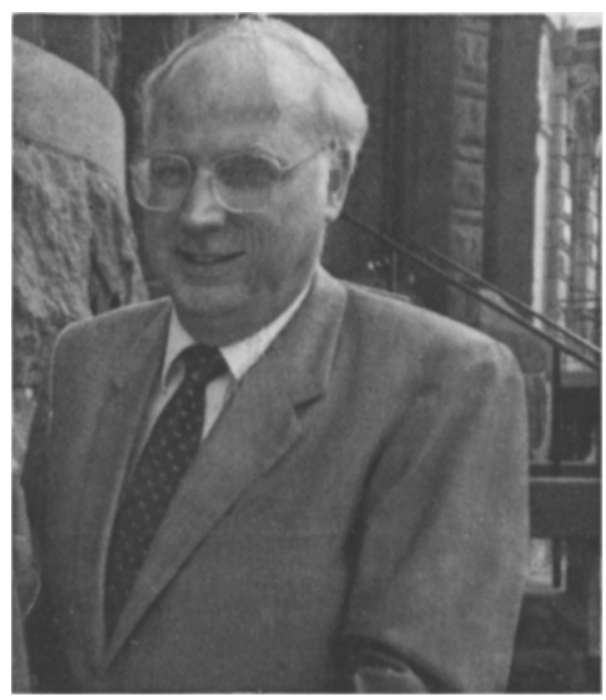

WALTER E. BEACH 